This item was submitted to Loughborough's Research Repository by the author.

Items in Figshare are protected by copyright, with all rights reserved, unless otherwise indicated.

\title{
Beyond beliefs: risk assessment technologies shaping patients' experiences of heart disease prevention
}

PLEASE CITE THE PUBLISHED VERSION

http://dx.doi.org/10.1111/j.1467-9566.2011.01406.x

\section{PUBLISHER}

Blackwell Publishing (@ 2011 The Authors. Sociology of Health \& Illness / ( 2011 Foundation for the Sociology of Health \& Illness/Blackwell Publishing Ltd.)

\section{VERSION}

AM (Accepted Manuscript)

\section{LICENCE}

CC BY-NC-ND 4.0

\section{REPOSITORY RECORD}

Saukko, Paula, Hannah Farrimond, Philip H. Evans, and Nadeem Qureshi. 2019. "Beyond Beliefs: Risk Assessment Technologies Shaping Patients' Experiences of Heart Disease Prevention”. figshare. https://hdl.handle.net/2134/14274. 
This item was submitted to Loughborough's Institutional Repository (https://dspace.lboro.ac.uk/) by the author and is made available under the following Creative Commons Licence conditions.

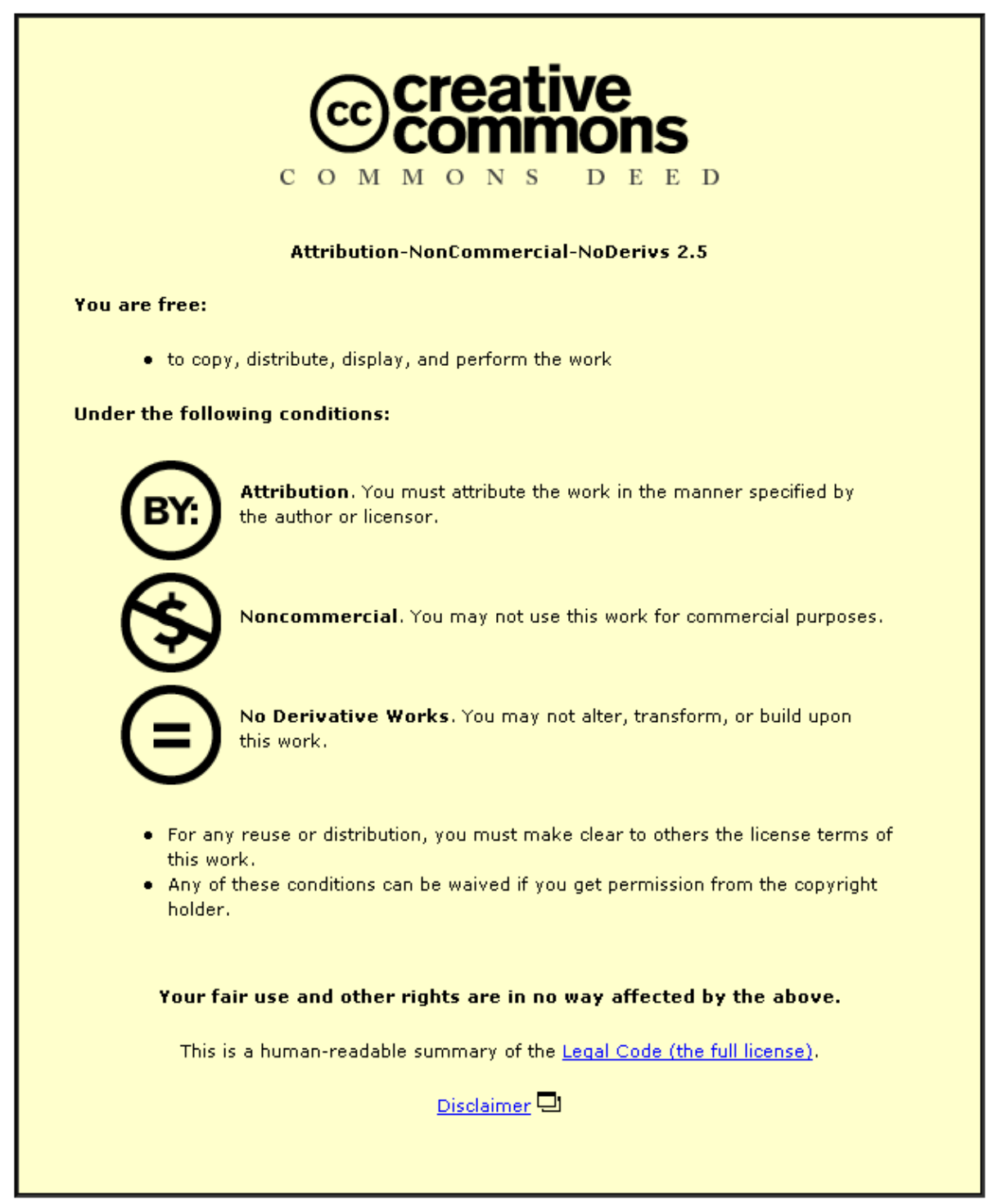

For the full text of this licence, please go to: http://creativecommons.org/licenses/by-nc-nd/2.5/ 
Saukko, P. Farrimond, H., Evans, P. \& Qureshi, N. (2012). Beyond beliefs: Risk assessment technologies shaping patient experiences of heart disease prevention, Sociology of Health and Illness, 34, 4, 560-75.

BEYOND BELIEFS: RISK ASSESSMENT TECHNOLOGIES SHAPING PATIENT EXPERIENCES OF HEART DISEASE PREVENTION

Keywords: heart disease, risk, primary prevention, cholesterol, statins, formal tools, protodisease 


\begin{abstract}
Social science research on lifestyle related diseases typically focuses on patient understandings and beliefs and takes the clinical risk for granted. We interviewed thirty healthy UK patients at high risk of heart disease, recruited from a family history trial, two weeks and six months after a discussion with a clinician about their risk, lifestyle and medications. The participants took four different paths: (i) pharmaceutical (most common, risk reduction with cholesterol lowering statins), (ii) mixed (statins and behaviour change), (iii) behavioural (behaviour change, focus on well-being) and (iv) “lost” (no prevention, difficult social/personal circumstances). Drawing on Berg we argue that CHD risk assessment technologies are formal tools that do not represent but generate high risk in a way that patients often experience lifestyle change as futile, because it rarely reduces their cholesterol to targets defined by the tools. We suggest social scientists studying incipient or "protodiseases," such as CHD risk, should not only focus on understandings but also investigate the technologies (and the associated guidelines, policies, clinical practice and pharmaceutical industry operations) that generate them and patient experiences of them. However technologies do not determine experience, and we also discuss elements that direct patients down other than the pharmaceutical path.
\end{abstract}




\section{INTRODUCTION}

Screening for and preventing lifestyle-related diseases is high on Western governments' agenda. The UK Department of Health (2008) has recommended screening all 40-75 year-olds for cardiovascular risk. Yet, there are no qualitative studies on how individuals who are healthy but at risk of heart disease actually experience screening and primary prevention.

Lay Understandings of Lifestyle Related Diseases

Health psychologists, using, for example, the self-regulatory model (Leventhal, Nerenz \& Steele,1984), study lifestyle-related disease focusing on cognitive processes, such as perceived causality or sense of control, suggested to mediate individuals’ responses to interventions. Sociologically oriented qualitative studies often reflect similar ideas, discussing how causal understandings (e.g. Schoenberg, Amey \& Coward, 1998) or "lay epidemiologies” (e.g. Davison, Davey-Smith \& Frankel, 1991) guide or might guide individuals’ preventive actions.

A systematic review of quantitative studies on causal beliefs about heart disease concluded that individuals most often attributed heart disease to lifestyle and chronic stress (French et al 2001). The belief that lifestyle causes heart attacks/diabetes has been observed to be associated with positive behavioural change in quantitative (Weinman et al 2000) and qualitative studies (Schoenberg, Amery \& Coward, 1998), although later research has suggested that this relationship is more complicated (French et al 2005). Beliefs that disease is down to luck or genes have been considered problematic, as fatalism is feared to render individuals less motivated to change behaviour. Qualitative 
research has suggested that individuals who understood their diabetes as inherited were less likely to have changed lifestyle (Hunt et al 1998, Schoenberg, Amey \& Coward, 1998). It has, however, also been suggested that family history could motivate healthy lifestyle (Hunt et al 2000).

Few studies have examined how individuals’ understandings develop after an intervention. Wiles (1998) observed that information delivered to patients after a heart attack about a quick recovery could either lead them to consider themselves "recovered" or hopeless. Both scenarios led the participants to abandon lifestyle advice. Lawton et al (2008) noted that participants' accounts of what had caused their diabetes shifted based on their experiences of treatment and disease progression i.e. if dietary changes were not effective in controlling glucose levels, they tended to attribute disease to genes. Marteau et al (2004) found that individuals, who had undergone genetic, as opposed to clinical, assessment of familial hypercholesterolaemia were more likely to believe in the effectiveness of cholesterol lowering statins.

\section{From understandings to technologies}

In the course of our research we observed that causal understandings did not necessarily or primarily guide our participants’ preventive strategies. Rather, we noticed that our participants' experiences were often dominated by risk assessment technologies and cholesterol lowering statins. To make sense of our observation we drew on Marc Berg's (1997) discussion of how “formal tools” generate the clinical states they seek to represent. CHD risk assessment technologies are formal tools in that they aim to represent or model risk of heart disease. Nevertheless,they do not reflect any 
encompassing risk but focus on very specific inputs, such as cholesterol and blood pressure levels, age, gender and smoking status. Based on these inputs the computational tools estimate whether an individual is at "high risk," defined as having over 20\% chance of developing CHD in the next 10 years (British Cardiac Society et al 2005). Those at high risk are recommended for treatment with statins by the UK government National Institute for Health and Clinical Excellence (NICE, 2006).

To make sense of how formal tools generate clinical phenomena Berg (1997) suggests studying their history. The history of CHD risk assessment is bound up with the development of pharmaceuticals. Greene (2007) has chronicled how cholesterol was associated with CHD already in the first Framingham studies in the 1950s, but as the early lipid lowering drugs proved dangerous or unpalatable and lifestyle interventions ineffective clinicians had lost interest in cholesterol by the 1970s. The transformation of one's cholesterol level into a popular icon for heart disease in the 1980s and 1990s was intimately associated with the development of the statin, an effective medication with fewer side effects and propagated by health campaigns, such as the US "Know Your Number” campaign (Greene, 2007: 173). Thus, rather than risk factor being identified first and treatment second, cholesterol only gained traction as a risk factor after the development of targeted drugs. This co-development of a risk factor and drugs has continued in the last decade, as the category of high cholesterol has expanded to encompass increasingly lower levels of cholesterol following trials, many of which have been funded by the pharmaceutical industry (Greene, 2007).

The CHD prevention in the USA has been very focused on cholesterol as indicated by the title of the main prevention guideliens, 'National Cholesterol education 
Programme' (NCEP), even if the programme recommends using the Framingham equation — which includes other risk factors, such as smoking, blood pressure and family history—when establishing risk and the need for treatment (NCEP 2001). The UK prevention policy has been more clearly founded on the use of multifactorial risk assessment tools. Will (2005), however, has documented the fact that the early CHD risk assessment tools in the 1990s were promoted mainly to determine prescribing thresholds in order to facilitate the rationing of statins in the public healthcare system. Similar to the US, the UK thresholds for high risk, cholesterol and prescribing have been pushed down following clinical trials (e.g. NICE, 2006).

The historical research indicates that CHD risk assessment technologies are designed as prescribing aids and embody a consensus between epidemiological research, public agencies focused on cost-effectiveness, such as the US NCEP and the UK, and pharmaceutical companies on how to define individuals at risk of heart disease, targeted for drug treatment. As discussed in the previous section, social science research on lifestyle related diseases tends to focus on patients' understandings and beliefs (residing in their cognition) that are viewed as separate from the taken-for-granted clinical risk. However, the estimate of CHD risk is not a natural fact but focuses attention on very specific aspects of reality, such as cholesterol, and articulates socially negotiated thresholds for high risk, cholesterol and prescribing. Against this we ask: How does the way in which contemporary assessment technologies generate CHD risk shape patients' experience?

To begin to answer this question Woolgar's (1991) notion of how technologies configure users by shaping their identities and constraining their actions is useful. 
Individuals defined as at high risk by the CHD tools end up with what Rosenberg (2007: 66) calls “protodisease.” Rosenberg (2007: 69) argues that these new incipient ills (high cholesterol or glucose) are detected by modern laboratory techniques but hark back to pre-germ theory moral conception of illness, where bad habits slide gradually into disease, a sanction for breaking behavioural norms. The reform of habits is also recommended for those at high CHD risk; the clinical guidelines accompanying assessment tools recommend lifestyle intervention to encourage patients to "make healthier food choices” (British Cardiac Society et al 2005: 2). However, the guidelines also set very specific biochemical targets for patients at high risk, including total cholesterol of less than $4.0 \mathrm{mmol} / \mathrm{l}$ or its reduction by $25 \%$ with lipid lowering drugs (British Cardiac Society et al 2005: 2). Clinicians, studied for an associated project, noted that such targets are difficult to achieve with lifestyle changes; they estimated that patients' cholesterol decreased "10\%" at best with behaviour change, whereas statins typically lowered cholesterol by “30\%.”1 The way in which CHD risk assessment technologies and associated clinical guidelines configure patients at high risk, thus creates a contradiction between the moral, public health agenda endorsing benefits of behaviour change and the precise biochemical targets, which frequently can only be achieved with drugs.

There are no studies on how real users, who have undergone CHD risk assessment and prevention, experience this contradiction. A focus-group study found that patients were frustrated with the restriction of heart disease prevention to the clinical monitoring of cholesterol levels and manipulating them with medications (Crinson et al 2007). Risk

\footnotetext{
${ }^{1}$ Focus-groups with clinicians $(\mathrm{n}=32)$ in 6 GP surgeries participating in the trial, conducted in 2007-2008.
} 
assessment technologies may play a greater role in influencing individuals' experience of CHD risk, because it is considered imperceptible (Angus et al 2005). As such, CHD risk is a prime example of contemporary risks discussed by Beck (1992), which require scientific knowledge and instruments to become constituted as hazards at all, as they cannot be assessed by everyday means such as felt pain and discomfort.

Still, risk assessment technologies, any more than any technology (see Oudshoorn, 2005), do not determine experiences. Whilst clinicians and some patients may consider conditions, such as blood pressure, detectable with specialist technologies only, individuals may have other means for assessing them. For example, patients frequently resort to physical and psychological states, such as headaches or feeling tense, to assess blood pressure (e.g. Leventhal, Nerenz \& Steele, 1984; Morgan \& Watkins, 1988; Benson \& Britten, 2002). In what follows we will examine how clinical and lay ways of configuring CHD risk interweave and occasionally collide with each other, illuminating the kinds of preventive paths they forge.

\section{METHODS}

Our qualitative study was nested within a trial examining the clinical utility of family history in cardiovascular risk assessment (for the protocol see Authors, 2009). The trial was conducted in 24 general practices in diverse socioeconomic areas in the UK East Midlands and South West. A total of 625 30-65 year-old patients completed the study; the inclusion criterion was being offered a cholesterol test and cardiovascular risk assessment as part of normal care. Individuals who had developed heart disease or diabetes or had been prescribed statins prior to the study were excluded. In the 
intervention arm the participants' family history of CHD was formally assessed using a self-completed questionnaire. Participants at high risk (British Cardiac Society et al 2005) were invited to a consultation with their clinician to discuss their risk and lifestyle/medications. We recruited "high risk" participants for a qualitative interview approximately two weeks and six months after the consultation. We used maximum variation sampling (Patton, 2002) in terms of gender, socioeconomic and family history status. We recruited both from intervention and control arms, seeking to ascertain possible qualitative differences. Recruitment was stopped when saturation was reached for the main topic of this article, that is, the role of risk assessment technologies in shaping patient experiences in the 6 months after the intervention, even if with slightly different outcomes.

The qualitative interviews were conducted by experienced researchers ( $\mathrm{AB}$ and BA) using the “discovery interview” (NHS Modernization Agency, 2001) format. We asked the participants to tell their experience chronologically, such as how they ended up having the cholesterol test, what they thought of being classed at high risk, what interactions they had had with clinicians and what, if anything, they had done with the information. In the second interview, six months later, the participants were asked how they had been getting on, what they thought of the risk assessment and their risk now and if they had had further contact with clinicians; each was also asked personalised followup questions based on a review of the first interview.

The interviews were recorded and transcribed. The transcripts were analysed using constant comparative thematic analysis, a selection of transcripts being inter-rater checked by both social science and clinical members of the team (Glaser, 1965). Our 
analysis was informed by the sociological tradition of discerning individuals" "careers" or paths when they progress through experience (e.g. Becker, 1963), which suited following patients in the aftermath of primary prevention intervention.

\section{RESULTS}

\section{Recruitment and main themes}

After receiving ethical approval we invited a total of 49 participants, mainly by phone, to the initial interview, of whom 38 (78\%) agreed to an interview (for details see Authors, 2010). Of the 38 initial participants, 30 were followed up at six months; one refused to give a follow-up interview, two could not be located and the last five were not contacted due to the impending maternity leave of the interviewer. The characteristics of the participants in terms of gender, age, socioeconomic and family history status and whether or not they were prescribed statins initially and at follow-up are shown in Table 1. All except for two participants were white.

[Table 1 here]

The interviews took place in 2007-2008. Most of the interviews were face-to-face and took place in the participants' home; ten of the initial and eight of the follow-up interviews were conducted by phone, when most convenient for the participant. We did not observe substantial differences between face-to-face and phone interviews.

Some of the participants were taking antihypertensives and were recruited to the study when having a blood-pressure check, others were recruited, for example, during 
health-checks or when consulting for unrelated illnesses. Thus, some of our participants, particularly the hypertensives, had been consulting their doctors over heart disease risk for some time, whereas for others the study was the first time they had been alerted to CHD risk.

In the initial interviews participants were often "shocked" about being identified at high risk, as they perceived themselves having a "healthy” lifestyle. They sought to normalise their risk and often planned some preventive actions (Authors, 2010). At follow-up our participants' experiences differed more substantially, and we identified four preventive paths: (i) pharmaceutical (most common, focused on decreasing risk with statins), (ii) mixed (engaged with prevention with statins and behaviour change), (iii) behavioural (focused on behaviour change) and (iv) "lost" (not engaged with prevention). The paths were shaped by an interaction between several elements, but each path was dominated by different elements. In Table 2 we summarise the main characteristics of the four paths in terms of (a) dominant elements, (b) how patients understood the causes of their risk, (c) participants’ personal and social circumstances and (d) the outcome of prevention as described by patients at follow-up.

[Table 2 to be inserted here]

To give a sense of the proportion of the different paths taken, thirteen, or nearly half, of our participants had followed the pharmaceutical path, the mixed path was followed by five participants, and the behavioural path by another five participants. Seven participants' experiences were categorised as "lost.” In what follows we will 
discuss the four paths through illustrative individual cases, which allow us to present the contextual and evolving nature of the experience.

\section{Pharmaceutical path}

The case of Howard (all names are pseudonyms) illustrates how risk assessment technologies, risk and cholesterol levels and managing them with statins ended up dominating the experience.

\section{Howard}

Howard was a part-time driver and handyman in his early sixties, who lived with his wife, Anne, also in the study and also classed at high risk of CHD. In the initial interview he told how he had been informed that his risk of heart disease was " $30 \%$ or 40\%.” He sought to normalise this risk, commenting that this information could be given “to practically everybody in the country at my age.” He doubted health advice, saying he agreed with the idea that being "overweight” would make you at risk but "disagreed” with the idea that "eating the wrong foods" would have anything to do with it, continuing that “we’ve got one book that says you can eat eggs and another book that says you can't eat eggs." He also added that in the "lists" "they" gave him on foods to eat "there was nothing there that you can grasp hold of," and that together with his wife they had concluded that they had a "reasonable” lifestyle, “not overdoing it, but not under-doing it.”

Howard's doctor had initially suggested he try lowering his cholesterol with diet. But after a month he had gone to the practice nurse, who had told him: "You can eat the 
best diet and best weight and God knows what, but you won't bring your cholesterol down. You've got to have tablets.” At follow up Howard told that statins had brought his cholesterol down from seven to three. He said that together with his wife they had initially tried "dieting” but "that's gone by the board now," and he was "experimenting” to see if the medications alone kept the cholesterol down:

H It's a bit of an experiment on my side, really, 'cause, um, [the cholesterol] went down to three. So now I’ve gone back to what I was doing before. Then when I have it taken again, if it’s gone up I know it’s me lifestyle, so I'll alter me lifestyle. It's no use altering your lifestyle and starving yourself of something you like if you don’t need to.

I Yeah, if the cholesterol is three?

$\mathrm{H}$ If the cholesterol stays the same, then I know ... the tablets are keeping it in check.

Howard was in the intervention arm but did not have a clinically significant family history; both initially and at follow-up he considered he was "inclined" to have high cholesterol, elaborating that the inclination was "in your genes and in your lifestyle.” The clinician had told him that his risk for CHD was down to his age, blood pressure and cholesterol (the main components of CHD risk assessment). Howard had been taking antihypertensive medications already before and was prescribed statins as part of the study and concluded the problem had been solved: "I'm dealing with the high blood pressure with the tablets, so me blood pressure isn’t high. And then they put me on 
statins ... and the cholesterol's come right down now. I'm down to three. So, there's no problem, you know.”

Howard attributed his risk of CHD to inheritance and his lifestyle. However, he considered his and Anne's lifestyle "reasonable," which he defined in opposition to excess, such as being overweight or overly rigid and "overdoing it” (see Crawford, 1984). He acknowledged that living more healthily could reduce his risk, and he had briefly tried small changes. Yet, he, directly and indirectly, communicated that the lifestyle advice he was provided was beyond what he considered "reasonable," referring to it in terms of "starving," evoking contradictions in health advice with regards to eggs (also e.g. Gabhainn et al 1999) and lack of access to healthy foods (also e.g. Clark et al 2010). In this situation, he had solved the problem of high risk and cholesterol by taking statins. Howard's experience is not primarily mediated by causal understandings. Rather his experience is shaped by the risk assessment technology, which constructed the problem for him in the first place in terms of CHD risk percentages and cholesterol levels. The risk, configured in terms of these abstract figures, could be effectively decreased with pharmaceuticals, which Howard considered solved the problem. Other elements, such as Howard's reluctance towards lifestyle advice, and his wife's and clinician's views, further supported his preventive strategy focused on medications without the need to disrupt his "reasonable" lifestyle.

Steve

In a couple of cases participants had gone down the pharmaceutical path having tried behaviour change first. To illustrate this we will discuss the case of Steve. 
Steve was in his early fifties, worked as a school mealtime assistant and lived on a council estate with his wife and teenage daughter. Steve was in the intervention arm and was identified with a positive family history. ${ }^{2}$ However, in the initial interview he concluded that health was " $90 \%$ " down to "the life you lead, I mean, if you go out boozing and womanising ... you're going to have a short life.” The nurse practitioner had given him "a long list” of things not to eat, and he had changed, for example, from eating beef and pork sausages to eating turkey ones. At follow-up he reported he had changed his diet and even drank soya milk, but both his bad and good cholesterol had gone down, he had had another birthday, which also increased his risk estimate, and his risk had been calculated as higher than initially. At this point his wife joined the conversation and summed up their experience:

Wife: Mind you, you were quite astonished, you had the test done and then [the nurse] said eat or try to eat this and that and we bought all the stuff and that and yet it went up, didn't it?

S Or that it...it was the bad one that went down...no, the good one that went down...

Wife: It reversed itself, wasn't it?

S Yeah, the bad one went down, but so did the good.

Wife: Like I said, you know, sometimes, eating the good stuff don’t help you. ... Cause it was expensive, the stuff I was buying as well.

\footnotetext{
${ }^{2}$ A positive family history was defined as having a first degree relative, who had developed heart disease before the age of 65 .
} 
At follow-up the clinician had prescribed him statins, telling him "there’s nothing else you can do,” and Steve concluded that his cholesterol was "hereditary anyway.”

Steve’s experience illustrates a discrepancy between the public health and clinical discourse, which emphasises the importance of lifestyle change for those at high risk, and CHD risk assessment and accompanying guidelines. The contradiction is created in particular by the specific target levels for cholesterol that are set by the guidelines and are difficult to achieve with lifestyle change. So, Steve was encouraged to change his behaviour, but this did not decrease his absolute risk and the balance between his highdensity lipoprotein or good cholesterol and total cholesterol. He concluded that his cholesterol did not behave in the way indirectly promised by the clinician, who gave him lifestyle advice (as the reasonable expectation is that, if one is given advice, following it should decrease the cholesterol identified as the problem), therefore it must have been inherited and needed to be controlled with drugs.

Other researchers have made similar observations. Lawton et al (2008) suggested that patients, whose glucose levels could not be controlled by lifestyle, reinterpreted their propensity to diabetes 2 as genetic. Marteau et al (2004) concluded that genetics based assessment increased trust in the effectiveness of medications. More broadly, Rose (2007) has argued that health conditions, from depression to cardiovascular disease, are no longer considered to be caused by life events or lifestyle but by genetically determined anomalous biochemistry to be corrected by pharmaceuticals that target the anomaly.

However, none of these studies have explored how risk assessment technologies fuel the reliance on pharmaceuticals and sometimes on genetic explanations. These 
technologies are designed to identify patients at high risk for pharmaceutical treatment (Greene, 2007; Will, 2005). This creates a dilemma for both clinicians and patients, who seek to adhere to the traditional, often moralistic public health dictum to change behaviour, which rarely helps the patients to decrease their cholesterol to target levels. Clinicians and patients may, subsequently, resort to genetic explanations to explain the seeming recalcitrance of cholesterol. Thus, the abandonment of lifestyle advice is not necessarily or primarily driven by causal understandings. Rather, genetic understandings become a post hoc rationalisation to make sense of a situation where cholesterol has defied expectations and has not decreased to recommended levels despite the patients' efforts to change their habits. Yet, Steve's preventive strategies are not determined by technologies and clinical recommendations only. Similar to Howard's case, Steve’s focus on pharmaceuticals is also supported by his wife and their joint experience of lifestyle change as cumbersome and costly.

\section{Mixed path}

The mixed path, characterised by prevention with both medications and lifestyle changes and frequently sustained by a supportive family and clinicians, is illustrated by the experience of Jean.

Jean

Jean was a homemaker in her early sixties, whose husband drove a taxi. She was in the control arm but volunteered in the initial interview that her father had died of heart 
disease in his late fifties, which had made her aware of risk of heart disease. In the initial interview Jean related that after the risk assessment she had been prescribed antihypertensives and started "thinking” more about her cooking, although considered that she ate "fairly sensibly." She had already altered her cooking practices before in order to support her husband, who had suffered a mini-stroke a couple of years earlier, in lifestyle change. At follow-up Jean had been prescribed statins, because her cholesterol had not decreased sufficiently, and her clinician had suggested to her that her cholesterol "might not be what you eat, it might just be hereditary." She had, however, maintained healthier eating and cooking habits and continued to "have more fruit, trying to keep off pastry stuff, grilling, as much as I can, not using the frying pan.” Jean also continued to support her husband in a healthier lifestyle, for example, by putting "a little bowl of fruit out” to entice him. On his behalf, her husband had bought her an exercise bike for Christmas, which she used twice a day when watching television; the bike stood next to the television in the lounge during the interview.

At follow-up Jean concluded that "the tablets I'm on have lowered the blood pressure and are lowering the cholesterol.” Later in the interview Jean contemplated on the effects of her lifestyle changes: “while I'm watching me diet I'm hopefully getting less at risk.” Yet, she struggled to assess the effect of her behaviour changes on her cholesterol:

J Well, I don't know, [the cholesterol going down] could be a combination of the tablets and watching me diet more, really.

I But before you went on the statins? 
J Before I went on the statins ...well, I don't think [the cholesterol went down], that's why we went on them.

I Because it didn't have much of an effect?

J No, it didn't, not at that time, anyway, whether in the long term it might have done, I don’t know.

Jean's understandings of the cause of her risk, her clinician's casual comments about her cholesterol being hereditary, her understanding of her previous lifestyle as "sensible" and her spouse also being at risk were rather similar to Howard's and Steve's situations.

Despite these similarities, patients taking the mixed path, such as Jean, maintained their behaviour change. The distinctive feature of these participants' experience was that they were supported by, or supported, other family members in behaviour change, which in Jean's case took a distinctly gendered form of taking responsibility for her husband's lifestyle (Radley \& Green, 1996, on family support in general Knutsen \& Knutsen, 1991). Jean and others classed in the mixed path did not necessarily experience lifestyle change as pleasurable; but they did not experience it as negative the way participants taking the pharmaceutical path did, and at follow-up they had integrated the changes into their everyday routines.

However, the risk assessment technologies also shaped the experience of those on the mixed path. The CHD risk assessment initially identified Jean at risk and identified elevated cholesterol as one of the key factors. Subsequently, the risk assessment guidelines indicated that that her lifestyle changes had not reduced her cholesterol to 
target levels and that she needed medications. At follow-up she was aware that medications had reduced her blood pressure and cholesterol. However, Jean struggled to assess the effects of her lifestyle changes, hoping they were lowering her risk. Similar to Steve's case, Jean's experience highlights the contradiction between public health messages on benefits of lifestyle change and the logic of the risk assessment framework, which cast doubt on the effectiveness of behaviour change.

The behavioural path

The behavioural path, characterised by behaviour change and the use of embodied sensations to assess risk, is illustrated by the experience of Richard.

\section{Richard}

Richard was an engineer in his late fifties and lived with his wife; his adult daughter lived close by with her family. He was in the control arm and did not discuss heart disease in relation to family history in the initial interview. He had been identified with high cholesterol years ago and had changed his lifestyle, shifted to "granary bread" and still "[ate] loads of fruit and veg [and] exercise[d].” He also told that he played golf, bowled and danced with his wife. However, when he changed his behaviour his cholesterol did not go down. After the risk assessment within the study his doctor had suggested he take medications to reduce his cholesterol, but Richard said he was not "one to pop pills” and said he would rather do it "naturally.” At follow-up Richard had done more exercise and joined a gym where he went together with his adult daughter, noting 
they "boosted" each other. He had lost nearly a stone in weight. He had not further discussed CHD with his doctor. When asked if he felt different about his risk of heart disease, he replied: I don’t feel so bad, you know, I feel better for going to the gym, if you like. ... I feel better for it, so maybe little less [at risk] perhaps.

Richard did not discuss possible causes of his risk much, but at follow-up he stated that, based on his experiences, he had “no control over” his cholesterol and continued to reflect on his sister who had "high cholesterol, as well. So, whether that's anything to do with it or not, I don’t know.” Richard's experience illustrated an interesting case where he had been committed to lifestyle change long-term, yet had not seen it produce effects in terms of decreased cholesterol, leading him to conclude that he could not control it and entertaining the possibility his high cholesterol was hereditary. Such frustrating experiences and understandings could have led Richard to abandon behaviour change. But, supported by his family and having had a long history of trying to lead a healthy lifestyle as well as being reluctant to take medications on the grounds they were "unnatural” (also e.g. Benson \& Britten, 2002), Richard sustained behaviour change.

Richard's experience is partly shaped by CHD risk assessment technologies, which identified him at risk and, in the past, had indicated that his behaviour change had not decreased his cholesterol. Rather than stay fixated on the clinical measure, Richard had resorted to embodied sensations as an alternative means for appraising the effects of his actions. Interestingly, all participants, who had changed their behaviour but were not taking statins at follow-up for varied reasons (doubts about medicines, side-effects or not being offered medications by their clinicians), commented on enhanced physical well- 
being and associated this with being less at risk. The comments varied from mentions of enhanced general well being ("feeling much better") to enhanced ability to perform everyday actions (walk up hills “without huffing and puffing”); several, including Richard, mentioned weight loss.

Embodied sensations have been considered a problematic way of assessing imperceptible conditions, such as blood pressure (Morgan \& Watkins, 1988), because they can mislead individuals about need for treatment. Richard's case illustrates that embodied sensations can be an important motivational factor for lifestyle change. Further, we argue that Richard “configures” heart disease risk differently from clinical assessment. Rather than evaluate his risk based on specific clinical measures (cholesterol etc), he assesses his risk in terms of broader embodied sense of health or quality of life ("well being”). Even if Richard seems a model patient in terms of the public health recommendation of behaviour change, in terms of CHD risk assessment his actions seemed not to produce "real” results (on technologies and "real” representations see Latour, 1998). Similar to Steve's and Jean's cases, Richard's experience highlights the contradiction between lifestyle advice and CHD risk assessment for patients at high risk, although each had a different outcome.

The lost path

Participants classed as taken the lost path were not engaged with either medications or lifestyle change and their experience was frequently marked by overwhelming personal and/or social circumstances. To illustrate the lost path we will discuss the experience of Gill; she is an "intense” case (see Patton, 2002: 243) in that her 
circumstances were more difficult than of most others, but they highlight the way in which these participants often experienced multiple health, social and personal difficulties simultaneously.

\section{Gill}

Gill was in her fifties and at the time of interview she was out of work. She was caring for her disabled husband as well as her elderly father-in-law; the family had recently lost their housing and were living in makeshift accommodation in the countryside. Both Gill and her husband had experienced multiple health problems. She had originally contacted the doctor because of "tightness" in the chest, her cholesterol was identified as high, but not as high as it had been some time before, after which she had lost weight. Gill was in the control arm but volunteered that there was "no reason to believe that it's anything hereditary, because mum and dad, they died of cancer.” Gill said that the doctor had told her they could not prescribe her tablets to lower the cholesterol, because she had thyroid problems.

At follow-up Gill had not changed anything. She spent a good while talking about her kidneys that were recently found to be "not working” and her husband's health issues, and said she was dissatisfied with doctors, who kept "pooh poohing” her and making her feel like she was "a bit of a waste of space” when, for example, she asked them to take her blood pressure. She said she thought "eating wrong foods" made cholesterol high but continued she had "no idea at all" what made cholesterol high and wondered if the cheese, olives and yogurts she ate increased cholesterol. Most people on the lost path concluded at follow up that their risk was the same as before as they were aware they had 
not done anything different. Gill also did not think her risk had changed during the study period but thought she might be less at risk than when she was heavier. Still, she considered her "stress levels” put her at risk and continued that "not having any money," “[partner's] problems” and being "prone to paranoia” stressed her out. She concluded her chest pains and stress were linked:

I think it's all due to me not knowing about my health necessarily and not feeling $100 \%$ and having to look after [partner] and his father, causes me to have these chest pains, and I think that's where these chest pains are coming from.

Gill's case illustrates how difficult personal and social circumstances had overwhelmed her ability to engage with heart disease prevention, even if she was concerned or even anxious about her overall health. Gill's experience was typical for those whose experiences we classed as following the lost path in that it was characterised by difficult social circumstances, such as financial and housing problems, as well as physical and mental health problems, which all made the prospect of heart disease fade into the background in relation to the pressing and constantly evolving problems. Participants following the lost path, including Gill, also had lower socioeconomic status and frequently had poor communication with their clinicians, often being confused or unclear about preventive actions or treatments and feeling ignored by professionals. In Gill's case all these elements came together, which also illustrates the fact that difficulties tended to cluster in this group. 
It has been observed that lower socioeconomic status correlates strongly with heart disease (Marmot \& Elliot, 2005). Preliminary findings of a Canadian study found that deprived men could not engage with CHD prevention (Savage, Dumas \& Bergeron, 2009), and individuals with low SES receive poorer care from their clinicians (Hart, 1971). Therefore, in Gill's cases, as well as in most other cases in the lost group, the obstacle for multidimensional prevention is not reductionist technologies but deprivation, which affects individuals' lives, physical and mental health and treatment in clinical settings and needs to be addressed through broad social programmes addressing health and social inequality.

\section{CONCLUSION}

When we initiated our qualitative study, nested within a family history trial, we wanted to explore, whether and how a formal family history assessment might shape our participants’ experiences. Somewhat to our surprise we did not observe substantial differences between the experiences of participants in the intervention and control arms or between those who had and those who did not have a clinically significant family history of CHD. Those participants who had been assessed to have a positive family history usually had a clearer understanding of CHD running in their family than others. Still, nearly all our participants understood their risk to be partly inherited, partly due to lifestyle, indicating that such understanding has become "common sense," as observed by Davison, Davey-Smith and Frankel (1991).

Further, understanding heart disease as partly inherited did not necessarily or primarily influence our participants’ preventive strategies. Rather, the experiences of our 
participants were often dominated by CHD risk assessment technologies, cholesterol levels and cholesterol reducing statins. Drawing on Berg's (1987) work on formal tools we noted that CHD risk assessment does not "reflect” risk but generates it by focusing attention and action on very specific elements, such as cholesterol. The risk assessment technologies and guidelines shape patients' and clinicians' experiences in three main ways. Firstly, they generate measures of risk, such as the chance of developing CHD in the next ten years (in percentages). Secondly, the technologies and guidelines create expectations, such as target levels for cholesterol. Thirdly, the CHD prevention framework provides rewards, such as sense of safety (of not being at risk) for reaching target levels. The risk assessment and treatment framework often creates a situation where lifestyle change seems unnecessary or futile; thereby disempowering both clinicians and patients in their effort to reduce patients' behaviour as it does not seem to translate to real, measurable improvements.

However, technologies do not determine experiences and not all our participants progressed down the "pharmaceuticals only" path. Patients on the mixed and behavioural paths had integrated some of the lifestyle advice into their everyday lives, which was associated with family support or motivated by embodied sensations of well-being. However, risk assessment technologies also shaped these experiences, casting doubt on the effectiveness of behaviour change, which did not seem to have "real" effects, as measured by cholesterol targets. These findings indicate that if one wants to encourage patients at high risk of CHD to change lifestyle, it might not be a good idea to be fixated on clinical measures, such as cholesterol. Rather, it might be best to emphasise broader benefits of lifestyle change for general health, quality of life and mobility i.e. well-being, 
which, in the end, might be a more appropriate indicator of overall health than total cholesterol. Our study also confirms that family plays a key role in prevention (e.g. Knutsen \& Knutsen, 1991), and that social deprivation hampers the ability of individuals to take care of their health. Deprivation cannot necessarily be ameliorated by clinical practice, except that it is often perpetuated by the tendency of clinicials to provide deprived individuals poorer care than the norm, according to the well-known inverse-care law (Hart, 1971).

Overall, the trouble with much social science research on lifestyle related diseases is that it concentrates on patients' understanding and takes the clinical risk for granted. Thus, research often views the root of any problems, such as neglect of lifestyle advice, in patients' cognitive processes (understandings and beliefs). We acknowledge that risk assessment technologies operate partly through understandings by directing attention to biochemical targets. Other understandings, such as considering heart disease risk partly hereditary or health advice unreasonable, also shaped the experiences of our participants on the pharmaceutical path. However, we argue that the focus on understandings obliterates the way in which risk assessment technologies and clinical guidelines shape individuals’ experiences of lifestyle related diseases and often drive pharmaceuticalization. We suggest social scientists studying the increasingly prominent incipient or “protodiseases” (Rosenberg, 2007) pay critical attention not only to patients' cognition but also to the way in which these conditions are being created in specific ways by the risk assessment framework, which encompasses technologies, public policies, clinical guidelines and practice as well as industry operations. 
Our study is the first to explore the experiences of healthy patients at high risk of CHD undergoing primary prevention intervention, which forms a key part of Western government's health policy. Previous studies have all focused on experiences of secondary prevention i.e. on individuals who have already developed heart disease and where issues, such as being cured or fixed and loss of physical strength become important (e.g. Radley \& Green, 1986; Wiles, 1998, Ononeze et al 2006). Focusing on those at high risk reveals how the category as such, with its orientation towards treatment, shapes the experience of those classified in this way, regardless of whether or not they take pharmaceuticals alone. However, as fewer participants had maintained their behaviour change (in the mixed and behavioural paths) our results in terms of what sustains behavioural change are indicative only. For this reason, it might be interesting to explore the experiences of those at moderate risk of CHD, who may not be recommended medications so readily. 
References:

Angus, J., Evans, S., Lapum, J., Rukholm, E., St Onge, R., Nolan, R., et al. (2005). 'Sneaky disease': The body and health knowledge for people at risk of coronary heart disease in Ontario, Canada, Social Science \& Medicine, 60, 2117-2128.

Beck, U. (1992). Risk society: Towards a new modernity. London: Sage.

Becker, H. (1963). Outsiders: Studies in the sociology of deviance. New York: Free Press.

Benson, J. \& Britten, N. (2002). Patients’ decisions about whether or not to take antihypertensive drugs: qualitative study, BMJ, 326, 103.

Berg, M. (1997). Of forms, containers, and the electronic medical record: Some tools for a sociology of the formal, Science, Technology \& Human Values, 22, 4, 403-33.

British Cardiac Society, British Hypertension Society, Diabetes UK, Heart, Primary Care Cardiovascular Society, \& The Stroke Association. (2005). JBS2: Joint British Societies’ Guidelines on prevention of cardiovascular disease in clinical care. Heart, 91(Supp 5), 1-52. 
Clark, AM., Duncan, AS., Trevoy, JE., Heath, S., Chan, M. (2010) Healthy diet in Canadians of low socioeconomic status with coronary heart disease: Not just a matter of knowledge and choice. Heart Lung. May 7. [Epub ahead of print]

Crawford, R. (1984). A cultural account of 'health': control, release and the social body. In J.B. McKinlay (Ed.), Issues in the political economy of health care. London: Tavistock.

Crinson, I, Shaw, A., Durrant, R., De Lusignan, S \& Williams, B. (2007). Coronary heart disease and the management of risk: Patient perspectives of outcomes associated with the implementation of the National Service Framework targets, Health, Risk \& Society, 9, 359-373.

Davison, C., Davey-Smith, G., \& Frankel, S. (1991). Lay epidemiology and the prevention paradox: the implication of coronary candidacy for health education. Sociology of Health and Illness, 13(1), 1-19.

Department of Health (2008). Putting prevention first: Vascular checks: risk assessment and management. London: Department of Health.

French, D., Senior, V., Weinman, J. \& Marteau, T. (2001). Causal attributions for heart disease: A systematic review, Psychology \& Health, 16, 77-98. 
French, D., (2005).

Gabhainn, N., Kelleher, S., Naughton, CC., Carter, AM., Flanagan, F. \& McGrath, MJ. (1999). Socio-demographic variations in perspectives on cardiovascular disease and associated risk factors, Health Education Research, 14(5), 619-28.

Glaser, B. (1965). The constant comparative method of qualitative analysis, Social Problems, 12(4), 436-445.

Greene, J.A. (2007). Prescribing by numbers: Drugs and the definition of disease. Princeton: Princeton University Press.

Hart, T. (1971). The inverse care law, The Lancet, 297(7696), 405-12.

Hunt, K., Davison, C., Emslie, C. \& Ford, G. (2000). Are perceptions of a family history of heart disease related to health-related attitudes and behaviour? Health Education Research, 15(2), 131-143.

Hunt, L., Valenzuela, M. \& Pugh, J. (1998). Porque me toco a mi? Mexican-American diabetes patients’ causal stories and their relationship to treatment behaviours, Social Science \& Medicine, 46, 959-969. 
Imperial Cancer Research Fund OXCHECK study. (1995). Effectiveness of health checks conducted by nurses in primary care: final results of the OXCHECK study. BMJ; 310: 1099-1104.

Keenan, J. (2007). QOF indicators. Available at (accessed January 31, 2011): http://www.webjeannie.co.uk/index.htm

Knutsen, S. \& Knutsen, R. (1991). The Tromso survey: the family intervention studythe effect of intervention on some coronary risk factors and dietary habits, a 6year follow-up study, Preventive Medicine, 20, 197-212.

Latour, B. (1998). How to be iconophilic in art, science and religion? In C.A. Jones \& P. Galison (eds.). Picturing science, producing art (pp. 418-440). London: Routledge.

Lawton, J., Peel, E., Parry, O. \& Douglas, M. (2008). Shifting accountability: A longitudinal qualitative study of diabetes causation accounts, Social Science \& Medicine, 67, 47-56.

Leventhal, H., Nerenz, DR. \& Steele, DJ. (1984). Illness representations and coping with health threats. In A. Baum, S.E. Taylor \& J.E. Singer (eds.) Handbook of psychology and health (pp. 219-252). London: Lawrence Erlbaum. 
Marmot, MG. \& Elliott, P. (2005). Coronary heart disease epidemiology: From aetiology to public health. $2^{\text {nd }}$ edition. Oxford: Oxford University Press.

Marteau T., Senior V., Humphries SE., et al. (2004) Genetic Risk Assessment for FH Trial Study Group. Psychological impact of genetic testing for familial hypercholesterolemia within a previously aware population: a randomized controlled trial. American Journal of Medical Genetics, 128A:285-93

Morgan, M. \& Watkins, CJ. (1988). Managing hypertension: beliefs and responses to medication among cultural groups, Sociology of Health and Illness, 10, 561-78.

National Institute for Health and Clinical Excellence (NICE). (2006). Statins for the prevention of cardiovascular events in patients at increased risk of developing cardiovascular disease or those with established cardiovascular disease. Available at (accessed January 31, 2011): http://www.nice.org.uk/TA094.

NHS Modernization Agency. (2001). Discovery interviews. Available at: http://66.102.9.104/search?q=cache:vj9Zoz0qIswJ:www.modern.nhs.uk/servicei mprovement/1338/4668/CHD\%2520Discovery\%2520Interviews.pdf+discovery+i nterviews\&hl=en

Ononeze V., Murphy, A.W., Byrne, M., Bradley, C. \& Macfarlane, A. (2006) Patients and health professionals' perspectives on the sociocultural influences on 
secondary cardiac behaviour: a qualitative study of the implications in policy and practice, Family Practice, 23(5), 587-96.

Oudshoorn, N. (ed.) (2005). How users matter: The co-construction of users and technology. Massachusetts: MIT Press.

Patton, MQ. (2002). Qualitative evaluation and research methods. $2^{\text {nd }}$ ed. London: Sage.

Radley, A. \& Green, R. (1986). Bearing illness: Study of couples where the husband awaits coronary graft surgery, Social Science \& Medicine, 23(6), 577-85.

Rose, N. (2007). The politics of life itself: Biomedicine, power and subjectivity in the twenty-first century. Princeton: Princeton University Press.

Savage, M., Dumas, A., Bergeron, C. (2009). Lifestyles of socially and materially deprived men suffering from heart disease: A question of instability and despair. Paper presented at the BSA Medical Sociology Annual Conference, Manchester, September 3-5.

Schoenberg, NE., Amey, CH. \& Coward, RT. (1998). Stories of meaning: lay perspectives on the origin and management of noninsulin dependent diabetes mellitus among older women in the United States, Social Science \& Medicine, 47, 2113-45 
Weinman, J., Petrie, K., Sharpe, N. \& Walker, S. (2000). Causal attributions in patients and spouses following first-time myocardial infarction and subsequent lifestyle change, British Journal of Health Psychology, 5, 263-73.

Wiles, R. (1998). Patients’ perceptions of their heart attack and recovery: The influence of epidemiological 'evidence' and personal experience. Social Science \& Medicine, 46(11), 1477-1486.

Will, C. (2005). Arguing about the evidence: readers, writers an inscription devices in coronary heart disease risk assessment, Sociology of Health and Illness, 27, 6, 780-801.

Woolgar, S. (1991). Configuring the user: The case of usability trials. In J. Law (ed.). The sociology of monsters: Essays on power, technology and domination (pp.57-102). London: Routledge. 
TABLE 1

\begin{tabular}{|l|l|}
\hline Gender & \\
\hline Female & 10 \\
\hline Male & 20 \\
\hline Age & \\
\hline $30-49$ & 2 \\
\hline $50-59$ & 11 \\
\hline $60-65$ & 17 \\
\hline Socioeconomic status & \\
\hline I-II (managerial \& & 10 \\
\hline professional) & \\
\hline III-VI (intermediate) & 5 \\
\hline VII-VIII (manual and not & 15 \\
\hline working) & \\
\hline Arm of study & 10 \\
\hline Control & 20 \\
\hline Intervention (family & \\
\hline At 2 weeks & \\
\hline & \\
\hline
\end{tabular}

${ }^{3}$ Eleven of the twenty had a clinically significant family history. 


\begin{tabular}{|l|l|}
\hline At 6 months & 20 \\
\hline
\end{tabular}

Table 1. Characteristics of participants

${ }^{4}$ Two of the 16 had stopped taking the medications at follow-up due to side-effects.

TABLE 2

\begin{tabular}{|c|c|c|c|c|}
\hline & $\begin{array}{l}\text { Dominant } \\
\text { elements }\end{array}$ & Cause & $\begin{array}{l}\text { Personal \& } \\
\text { social } \\
\text { circumstances }\end{array}$ & Outcome \\
\hline $\begin{array}{l}\text { Pharmaceutical } \\
\text { path }\end{array}$ & $\begin{array}{l}\text { Reducing } \\
\text { cholesterol } \\
\text { and risk with } \\
\text { statins }\end{array}$ & $\begin{array}{l}\text { Hereditary \& } \\
\text { behaviour, } \\
\text { sometimes } \\
\text { hereditary } \\
\text { post hoc }\end{array}$ & $\begin{array}{l}\text { Varied SES } \\
\text { clinician and } \\
\text { family support } \\
\text { for statins }\end{array}$ & $\begin{array}{l}\text { Cholesterol } \\
\text { and risk down, } \\
\text { not concerned } \\
\text { anymore }\end{array}$ \\
\hline Mixed path & $\begin{array}{l}\text { Family support } \\
\text { statin use and } \\
\text { behaviour } \\
\text { change }\end{array}$ & $\begin{array}{l}\text { Hereditary \& } \\
\text { Behaviour }\end{array}$ & $\begin{array}{l}\text { Varied SES, } \\
\text { family \& } \\
\text { clinician } \\
\text { support } \\
\text { for behaviour } \\
\text { change \& } \\
\text { statins }\end{array}$ & $\begin{array}{l}\text { Statins brought } \\
\text { risk down, } \\
\text { effect of } \\
\text { behaviour } \\
\text { change? }\end{array}$ \\
\hline $\begin{array}{l}\text { Behavioural } \\
\text { path }\end{array}$ & $\begin{array}{l}\text { Behaviour } \\
\text { change, focus on } \\
\text { embodied } \\
\text { sensations }\end{array}$ & $\begin{array}{l}\text { Hereditary \& } \\
\text { behaviour }\end{array}$ & $\begin{array}{l}\text { Varied SES, } \\
\text { some family } \\
\text { support for } \\
\text { behaviour } \\
\text { change }\end{array}$ & $\begin{array}{l}\text { Feeling better, } \\
\text { less at risk? }\end{array}$ \\
\hline $\begin{array}{l}\text { Lost } \\
\text { path }\end{array}$ & $\begin{array}{l}\text { Overwhelming } \\
\text { circumstances, } \\
\text { no preventive } \\
\text { actions }\end{array}$ & $\begin{array}{l}\text { Hereditary \& } \\
\text { behaviour }\end{array}$ & $\begin{array}{l}\text { Lower SES, } \\
\text { poor clinician } \\
\text { \& family } \\
\text { support, } \\
\text { difficult life } \\
\text { circumstances }\end{array}$ & $\begin{array}{l}\text { Risk perceived } \\
\text { the same }\end{array}$ \\
\hline
\end{tabular}

Table 2. Key features of the four preventive paths identified. 